\title{
Nodular Amyloidosis Overlapping and Polymyositis in a Patient with Skin Manifestations Lupus Fax: Case Report
}

\author{
Enéas Van Der Maas do Bem Filho, Laíza Maria dos Santos Couto, \\ Antônio Luiz da Costa Soares Jr., Pedro Paulo Andrade, Thiago Sande Miguel, \\ Sebastião Célio Horta Coelho Filho, Daniel Almeida da Costa, \\ Lívia Cristina de Melo Pino, Thayro Van Der Maas do Bem
}

The Medical School at the Center of Higher Education of Valença, Valença, Brazil

Email: professordanielfmv@gmail.com

How to cite this paper: do Bem Filho, E.V.D.M., dos Santos Couto, L.M., da Costa Soares Jr., A.L., Andrade, P.P., Miguel, T.S., Filho, S.C.H.C., da Costa, D.A., de Melo Pino, L.C. and do Bem, T.V.D.M. (2017) Nodular Amyloidosis Overlapping and Polymyositis in a Patient with Skin Manifestations Lupus Fax: Case Report. Journal of Biosciences and Medicines, 5, 33-40. https://doi.org/10.4236/jbm.2017.511005

Received: September 23, 2017 Accepted: November 17, 2017 Published: November 20, 2017

Copyright $\odot 2017$ by authors and Scientific Research Publishing Inc. This work is licensed under the Creative Commons Attribution International License (CC BY 4.0).

http://creativecommons.org/licenses/by/4.0/

\begin{abstract}
Amyloidosis is the result of fibrous and insoluble amyloid protein deposition in extracellular spaces of tissues and organs, including the skin. Through the analysis of medical records, clinical condition and laboratory tests, this article proposes a rare case report of an adult patient with symptoms and diagnosis of polymyositis, histopathology of nodular amyloidosis with skin lesions suggestive of lupus. The patient is still being followed at the dermatology clinic of Valença Medical School, in order to improve the prognosis and prevent the progression of existing symptoms.
\end{abstract}

\section{Keywords}

Nodular Amyloidosis, Polymyositis

\section{Introduction}

Amyloidosis, therefore, defines a disease heterogeneous group characterized by an extracellular deposition of a proteinaceous (amyloid) material, in a localized or systemic form, presenting well defined characteristics, such as homogeneous pink appearance under microscopy in traditional coloration, green birefringence in Congo red staining polarized light, non-derivative fibrillar structure, parallel laminar conformation, and high insolubility [1] [2] [3].

This disease is related to the dysfunction of several organs, among them the skin, due to a tissue infiltration of insoluble amyloid fibrillar protein deposits resistant to proteolysis. They may be primary or secondary, systemic or localized, 
genetic or acquired, being difficult to classify them [2] [3] [4].

Polymyositis and dermatomyositis are rare idiopathic inflammatory myopathies with an unknown autoimmune pathogenesis. It is believed that this process is triggered by external factors in genetically predisposed people. These pathologies may occur alone, or associated with malignancy or other connective tissue autoimmune diseases, such as systemic lupus erythematosus, Sjögren's syndrome, and others [5] [6]. Polymyositis is characterized by progressive and symmetrical proximal muscular weakness, in which dysphagia is observed in most patients. Dermatomyositis is identified by characteristic cutaneous manifestations preceding or following muscle weakness [5] [6] [7].

Systemic lupus erythematosus (SLE) is a chronic, multisystem inflammatory disease of unknown cause and autoimmune nature, characterized by the presence of several autoantibodies. It evolves with polymorphic clinical manifestations, with periods of exacerbations and remissions. Of not fully understood etiology, the disease development is linked to genetic predisposition and environmental factors such as ultraviolet light and some medications. It is a rare disease, affecting, more frequently, young women in the reproductive age [5] [8] [9] [10].

This study aims to present a rare case in the literature, of an adult patient with symptoms and diagnosis of polymyositis, but with histopathological nodular amyloidosis and cutaneous lesions suggestive of lupus, in order to foster an individual and detailed investigation of each pathology, assimilating the data provided from the clinical examination and anamnesis with complementary methods.

\section{Case Report}

After being examined by the rheumatology clinic, a 58-year-old, white and male patient was referred to the dermatology outpatient clinic of the Luiz Gioseffi Jannuzzi School Hospital in the city of Valença, RJ, Brazil, with complaint of myalgia, paresthesia and paresis of the pelvic girdle, accompanied by cutaneous lesions on the scalp, face, ears, shoulder, back and neck that started approximately 3 years before with progression of the condition.

On examination, hyperemic and hypochromic macular lesions interspersed with areas of atrophy and well-defined borders, being infiltrative and painful in the auricle, suggesting chondrites (Figure 1). There are also unilateral lesions distally (Figure 2), cicatricial lesions on the back and other photo exposed areas (Figure 3) and cicatricial alopecia on the scalp (Figure 4).

A lesion cutaneous biopsy was performed in the malar region, whose histopathological findings revealed dermal nodules composed by extracellular eosinophilic material, showing clefts between the deposits and the atrophic epidermis characterizing the nodular amyloidosis.

Complementary tests, such as complete blood count, autoantibodies to anti-SSB/LA, anti-nuclear factor, anti-SM antibody, native anti-DNA antibody, anti-SCL 70 autoantibody, liver function tests, urine (physical characters, biochemical researches, sedimentscopy) did not present alterations, therefore, they 


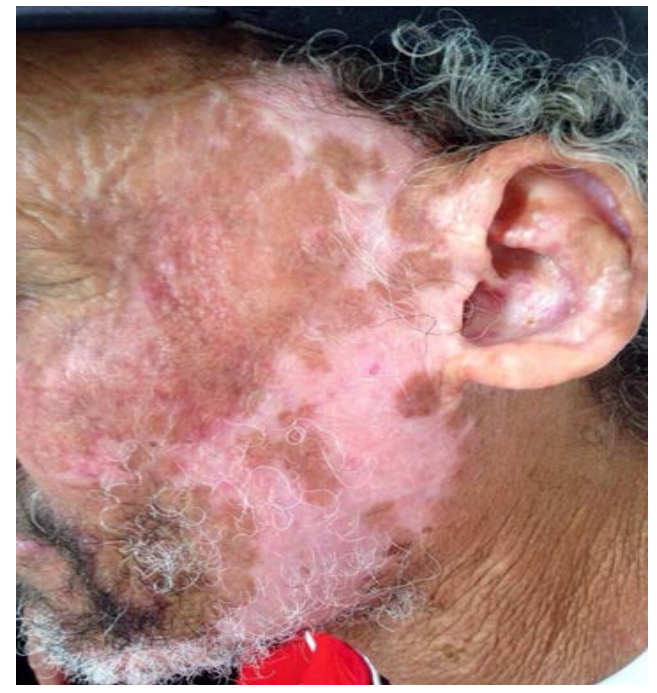

Figure 1. Erythematocytochromic macules with atrophy and chondritis in the auricle.

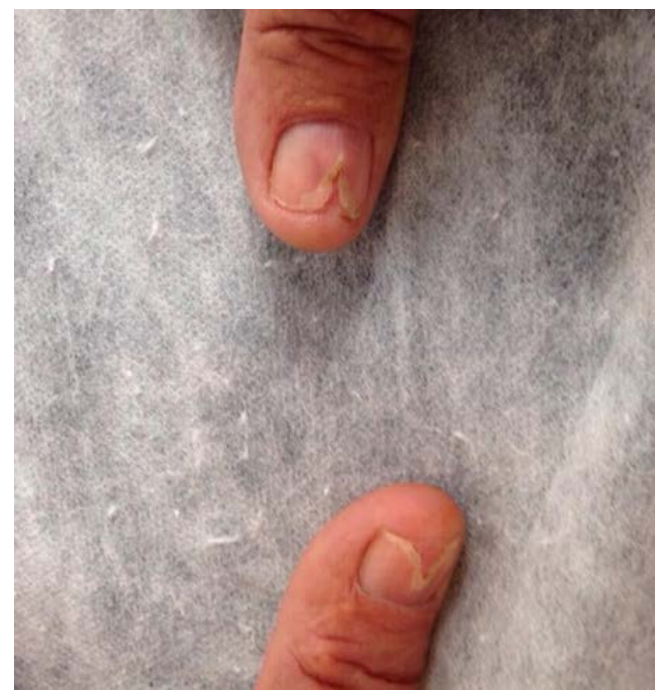

Figure 2. Distal ungual lesions.

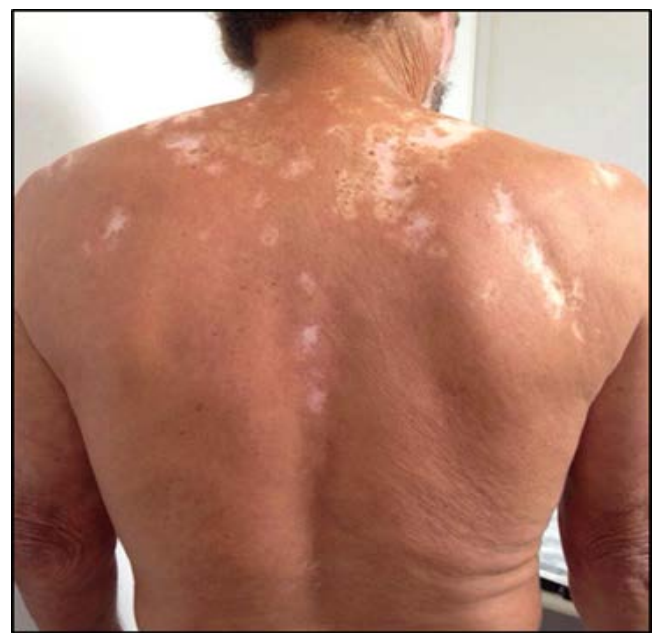

Figure 3. Scars lesions in exposed areas. 


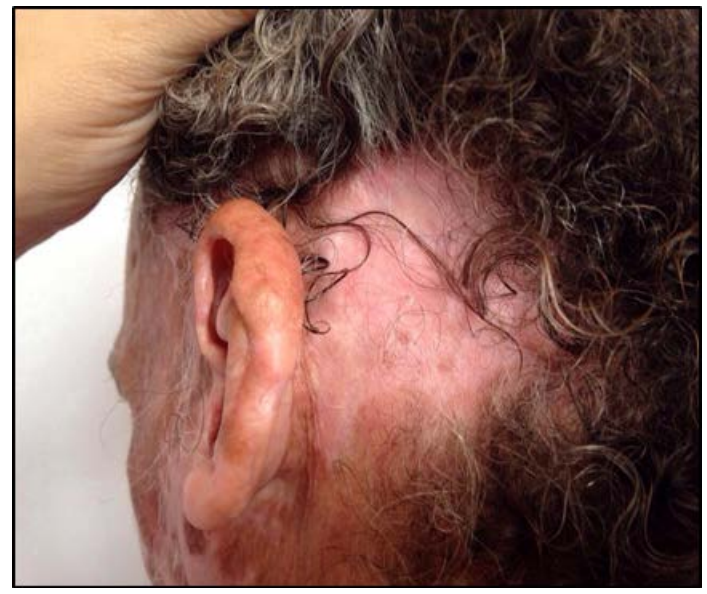

Figure 4. Plates of cicatricial alopecia.

were within the range of normality. In contrast, anti-SSA/RO antibodies which indicated lupus activity.

In addition to the significant increase in VHS, the creatine kinase (CK-total) dosage presented a result of 495.00 U.I./1 (reference value 25.00 to 195.00 U.I./1), which confirms, therefore, muscle alteration.

In the electromyography, the result indicated motor sensory polyneuropathy of axonal predominance affecting the four limbs, being more prominent in the lower ones. It was identified that the myo-graph had a diffuse myopathic pattern of proximal predominance in the upper and lower limbs.

Currently, the patient is being followed up by the Dermatology outpatient clinic of the Luiz Gioseffi Jannuzzi School Hospital in the city of Valença-RJ. Although the diagnosis has been determined, considering the unusual nature of the diseases in question, future tests will be proposed in order to guarantee control of the current situation and, mainly, an impediment with consequent worsening of clinical progression. As therapeutic measures, patient makes use of azathioprine $150 \mathrm{mg} /$ day and photo-protection.

This study counts with a patient that was previously and properly explained about its clinical picture and the importance of it, as well as the objectives of the present study. It was approved by the Research Ethics Committee of the Faculty of Medicine of Valença, and the patient was patient with the publication of his report.

\section{Discussion}

Among the amyloidosis cutaneous lesions, we can highlight those that occur as a localized primary form, being the form studied by the patient in question, so as to be evidenced by hyperemic and hypochromic macular lesions interspersed with atrophic regions and with very precise limits, of infiltrative and painful aspect located in the auricular pavilion and side portion of face. Recently described, the nodular form of amyloidosis is rare and is clinically characterized by single or multiple nodules of 1 to $3 \mathrm{~cm}$ in diameter, preferably located at the extremities 
or on the face. It is known that the epidermis over the lesion is atrophic. At the periphery of the amyloid deposits are numerous plasmocytic, which produce a large amount of localized immunoglobulin light chains, giving rise to the pathogenic amyloid deposit [11] [12] [13].

The cutaneous lesions of nodular amyloidosis are usually single or multiple papules-nodules (nodules or asymptomatic plaques), which are pinkish-brown and tend to affect the face, nose and periauricular areas, as well as genital areas, trunk and limbs. Such lesions are similar to those observed in primary systemic amyloidosis associated with plasmacytoid lymphoproliferative disease. The histopathological reveals a rectified epidermis and masses of amorphous eosinophilic material occupying the entire dermis extension, pressing the cutaneous appendages, and around vessels [11] [12] [14] [15]. The cutaneous biopsy performed by the patient revealed histopathological with dermal nodules composed of extracellular eosinophilic material, with fissures permeating the deposits, with atrophic epidermis, which corroborates with the nodular amyloidosis condition.

Since the patient is 58 years old, his age group is in agreement with that found in literature. The pathology also occurs in both sexes, with a mean age at diagnosis of 60.8 years [12] [14] [16]. Often the diagnosis is late, with the average duration of onset of lesions up to the diagnosis of 13.5 years. The process may have a chronic, localized or benign course; however, patients need a follow up and to be monitored for progression to systemic amyloidosis and plasmocytic dyscrasias, which occurs in about $7 \%$ to $50 \%$ of patients [12] [14] [16]. The patient in the present report claimed that his lesions had started about 3 years before which shows late diagnosis and its chronic course, which reveals the importance of early diagnosis and follow-up.

Initial symptoms are usually weakness and weight loss, later on the appearance of cutaneous lesions, particularly in the periorbital and facial regions, bone pain, more intense bleeding and, finally, those related to neuropathies [17] [18] [19] [20] [21]. The patient presented his with a complaint of myalgia, paranesthesia and paresis of the pelvic girdle, accompanied by cutaneous lesions on the scalp, face, ears, shoulder, back and neck, a course similar to that found in previous studies, which draws attention to the behavior.

The histopathology the patient was diagnosed with nodular amyloidosis, however his cutaneous picture suggests lupus. This is because cutaneous lupus lesions present initially with erythematous-atrophic lesions and with mild follicular keratosis and telangiectasias [10] [21]. They may be discoid or rounded, measuring from a few millimeters to a few centimeters in diameter and reaching photo exposed areas preferentially on the face, back of the nose, malar region, ears, eyelids, neck and scalp, where it leads to cicatricial alopecia, which may therefore explain the hyperemic and hypochromic macular lesions referred to above. In some cases, depigmentation (hyper, hypo or acromia, giving a vitiligo appearance), as well as involvement of the fingertips with keratosis and nail dystrophy, and, exceptionally, blisters may be observed, especially after sun exposure [11] [21] [22]. 
Polymyositis is a disease characterized by proximal muscle weakness and inflammation of the skeletal muscles. For the diagnosis of this pathology, criteria such as increased muscle enzymes, myopathic changes in electroneuromyography and evidence of muscle inflammation are used [6] [23] [24] [25]. The dosage of creatinoquinase (CK-total) resulted in 495.00 U.I./1, which confirms muscle alteration.

The electroneuromyography and anamnesis performed closed the diagnosis of polymyositis.

Histopathological examination performed with non-specific HE staining (Hematoxylin-Eosin) was sufficient for the conclusion of nodular amyloidosis. However, the use of a special dye (Red-Congo) would complement this diagnosis, since the amyloid substance is better visualized by this staining [2] [3] [4]. As for lupus simile lesions, they were clinically evidenced and confirmed by the positivity of the anti-SSA/RO antibodies.

This is a case of an adult patient with symptomatology and diagnosis of polymyositis, nodular amyloidosis histopathological diagnosis, however, without clinical presentation and, in addition, presenting cutaneous manifestations suggestive of lupus

The patient in question is being followed up in the dermatology department in order to prevent progression of existing symptoms. Currently it uses azathioprine $150 \mathrm{mg} /$ day and photoprotection. However, due to the unusual clinical picture appearance, the patient remains in follow-up to avoid complications and future aggravations of his pathological condition.

\section{Conclusions}

Although an anatomic-physiological pattern is studied, patients present different peculiarities, especially when they refer to diseases and their clinical manifestations. As for dermatology, it is known that it is correlated to several medical specialties, since the skin is the focus of clinical manifestations of diseases of different etiologies.

Finally, it is worth emphasizing the importance of routine follow-up, conducting examinations in order to obtain early diagnosis and, above all, the importance of professionals interdisciplinarity, reaffirming the fact that the medical clinic is responsible for a multitude of pathologies and these, almost always, relate to each other, defining the manifestations and prognoses of patients.

\section{References}

[1] Annes, M., et al. (1997) Amiloidose. Rev. Neurociências, 1, 7-13.

[2] Konopinski, J.C., Seyfer, S.J., Robbins, K.L. and Hsu, S. (2013) A Case of Nodular Cutaneous Amyloidosis and Review of the Literature. Dermatology Online Journal, 19,10 .

[3] Woollons, A. and Black, M.M. (2001) Nodular Localized Primary Cutaneous Amyloidosis: A Long-Term Follow-Up Study. British Journal of Dermatology, 145, 105-109. https://doi.org/10.1046/j.1365-2133.2001.04291.x 
[4] Moon, A.O., Calamia, K.T. and Walsh, J.S. (2003) Nodular Amyloidosis: Review and Long-Term Follow-Up of 16 Cases. Archives of Dermatology, 139, 1157-1159. https://doi.org/10.1001/archderm.139.9.1157

[5] Azulay, R.D. and Azulay, D.R. (2004) Dermatologia. 4th Edition, Guanabara Koogan, Rio de Janeiro, 664 p.

[6] Marie, I., Hachulla, E., Chérin, P., et al. (2005) Opportunistic Infections in Polymyositis and Dermatomyositis. Arthritis Care \& Research, 53, 155-165. https://doi.org/10.1002/art.21083

[7] Lupi, O. and Cunha, P.R. (2012) Rotinas de Diagnóstico e Tratamento da Sociedade Brasileira de Dermatologia. Editora Gen, Rio de Janeiro, 680 p.

[8] Mcelhone, K., Abbott, J. and Teh, L.-S. (2006) A Review of Health Related Quality of Life in Systemic Lupus Erythematosus. Lupus, 15, 633-643. https://doi.org/10.1177/0961203306071710

[9] Telles, R.W., Lanna, C.C.D., Souza, F.L., Rodrigues, L.A., Reis, R.C.P. and Ribeiro, A.L. (2013) Causes and Predictors of Death in Brazilian Lupus Patients. Rheumatology International, 33, 467-473. https://doi.org/10.1007/s00296-012-2372-X

[10] Wolfe, F., Petri, M., Alarcón, G.S., Goldman, J., Chakravarty, E.F., Katz, R.S., et al. (2009) Fibromyalgia. Systemic Lupus Erythematosus (SLE) and Evaluation of SLE Activity. The Journal of Rheumatology, 36, 82-88.

[11] Bohan, R. (1988) History and Classification of Polymyositis and Dermatomyositis. Nova Iorque. Clinics in Dermatology, 6, 3-8.

[12] Breatmatch, S.M. (2010) Amyloid and the Amyloidosis of the Skin. In: Burns, T., Breathnach, S., Cox, N. and Griffiths, C., Eds., Rook's Textbook of Dermatology, Wiley-Blackwell, 42-59.

[13] Lachance, A., et al. (2014) Nodular Localized Primary Cutaneous Amyloidosis: A Bullous Variant. Clinical and Experimental Dermatology, 39, 344-347. https://doi.org/10.1111/ced.12305

[14] Lachmann, H.J., Goodman, H.J., Gilbertson, J.A., Gallimore, J.R., Sabin, C.A., Gillmore, J.D. and Hawkins, P.N. (2007) Natural History and Outcome in Systemic AA Amyloidosis. The New England Journal of Medicine, 356, 2361-2371. https://doi.org/10.1056/NEJMoa070265

[15] Souza, J.J., et al. (2011) Amiloidose Localizada Cutânea Primária Nodular Relato de caso. Anais Brasileiros De Dermatologia, 86, 987-990. https://doi.org/10.1590/S0365-05962011000500018

[16] Hoffman, B.J. (1945) Sensitivity to Sufadizine Resembling Acute Disseminated Lupus Erythematosus. Archives of Dermatological Research, 51, 90-92.

[17] Bronner, M., Van Der Meulen, M., De Visser, M., et al. (2006) Long-Term Outcome in Polymyositis and Dermatomyositis. Nova Iorque. Annals of the Rheumatic Diseases, 65, 1456-1461. https://doi.org/10.1136/ard.2005.045690

[18] Esposito, A.C.C., Munhoz, T., Ocanha, J.P. and Miot, H.A. (2016) Syndrome in Question. Anais Brasileiros de Dermatologia, 91, 387-389.

https://doi.org/10.1590/abd1806-4841.20164298

[19] Travassos, A.R., Borges-Costa, J., Filipe, P. and Marques, M.S. (2013) Malignancy Associated with Dermatomyositis-A Retrospective Single-Center Study with 33 Patients. Acta Reumatológica Portuguesa, 38, 92-97.

[20] Ortigosa, L.C.M. and dos Reis, V.M.S. (2014) Dermatomyositis: Analysis of 109 Patients Surveyed at the Hospital das Clínicas (HCFMUSP), São Paulo, Brazil. Anais Brasileiros de Dermatologia, 89, 719-727. 
https://doi.org/10.1590/abd1806-4841.20143422

[21] Chahin, N. and Engel, A. (2008) Correlation of Muscle Biopsy, Clinical Course, and Outcome in PM and Sporadic IBM. Nova Iorque. Neurology, 70, 418-424. https://doi.org/10.1212/01.wnl.0000277527.69388.fe

[22] Ciber, J., Sibley, J. and Haga, M. (2001) Systemic Lupus Erythematosus and the Risk of Malignancy. Lupus, 10, 394-400. https://doi.org/10.1191/096120301678646128

[23] Hurd, K. and Barnabe, C. (2017) Systematic Review of Rheumatic Disease Phenotypes and Outcomes in the Indigenous Populations of Canada, the USA, Australia and New Zealand. Rheumatology International, 37, 503-521.

https://doi.org/10.1007/s00296-016-3623-Z

[24] Magro-Checa, C., Zirkzee, E.J., Huizinga, T.W. and Steup-Beekman, G.M. (2016) Management of Neuropsychiatric Systemic Lupus Erythematosus: Current Approaches and Future Perspectives. Drugs, 76, 459-483. https://doi.org/10.1007/s40265-015-0534-3

[25] Barros, R., Alves, M. and Dantas, M. (2006) Glomerulopatias-Patogenia clínica e tratamento. 2nd Edition, Sarvier, São Paulo, 288-298. 